\title{
Oral Lichen Planus and Features in the Short Chain Fatty Acid Pattern Produced by Colonic Fermentation
}

\author{
Umida A. Shukurova*, PhD; Olga E. Bekjanova, PhD, ScD \\ Tashkent State Dental Institute \\ Tashkent, Uzbekistan
}

\begin{abstract}
The aim of the study was to assess the content of short chain fatty acids (SCFAs) in feces of patients with different clinical forms of oral lichen planus (OLP).

Materials and Methods: The study included 139 patients with different clinical forms of OLP in the acute stage. The diagnosis of OLP was performed according to both clinical and histopathological criteria. Patients were distributed in four groups according to the clinical form of OLP. Group 1 included 36 patients with the reticular form of OLP; Group 2 included 34 patients with the exudative-hyperemic form of OLP; Group 3 included 27 patients with the erosive-ulcerative form of OLP; Group 4 included 42 patients with the bullous form of OLP. The four groups to be compared were randomized by sex and age. The control group consisted of 40 healthy, age-matched, randomly selected persons without clinical and instrumental signs of OLP and other diseases of the oral cavity. The concentration of SCFAs in feces was evaluated by gas-liquid chromatography. The profiles (specific concentration) of $\mathrm{C} 2, \mathrm{C} 3$, and $\mathrm{C} 4$ acids, the ratio of iso-acids to straight-chain acids (iso- $\mathrm{Cn} / \mathrm{Cn}$ ) and iso-C5/C5 were also calculated.

Results: Three types of SCFA changes reflecting the activity of certain groups of microorganisms were found. For all types of the SCFA disorders, we found a marked increase in the iso-C5/C5 ratio. The severity of dysbiosis increased with the severity of clinical forms of OLP. Changes in the qualitative and quantitative contents of SCFAs reflect the disturbances in gut microbiocenosis in LPO patients, which may be one cause for aggravation of the pathological process. (Int J Biomed. 2016;6(1):74-77.).
\end{abstract}

Keywords: oral lichen planus; short chain fatty acids; microbiota; dysbiosis.

\section{Introduction}

Lichen planus (LP) is a chronic systemic inflammatory disease that affects the skin and mucous membranes. LP occurs in 0.1 to $4 \%$ of the general population, most often in perimenopausal women. Oral LP (OLP) is a mucosal subtype of LP that most commonly occurs in middle-aged adults; the population frequency of OLP is $0.5 \%$ to $2.2 \%$. The etiology of this disorder remains uncertain. Several immunological mechanisms of its pathogenesis have been proposed, including antigen-specific cell-mediated immune response, nonspecific immunological mechanisms, autoimmune response, and humoural immunity [1]. OLP is the target of much controversy, mainly in relation to its pathogenesis and possible potential for malignancy. OLP is usually regarded as a multifactorial disease in which endogenous and exogenous

*Corresponding author: Umida A. Shukurova, PhD. Tashkent State Dental Institute. Tashkent, Uzbekistan.E-mail: shua1981@, $\underline{\text { mail.ru }}$ factors, in addition to genetic defects, can play a role in the formation and nature of the pathological process.

As is known, disorders of oral mucosa and the gastrointestinal tract may occur simultaneously as a manifestation of a generalized disorder. Human mucosal sites are colonized by an astonishing number of microorganisms of different genera (e.g., Bifidobacterium, Eubacterium, Fusobacterium, Escherichia and Candida). Most of these nonhuman cells are located in the gastrointestinal tract (GIT) where they exert protective (i.e., natural defense barrier and production of anti-microbial factors), structural (i.e., development of immune system and induction of $\operatorname{IgA}$ ), and metabolic (i.e., fermentation of non-digestible dietary residues, synthesis of vitamins and ion absorption) functions [2].

Important effects of these microorganisms and their products have been demonstrated not only in the GI tract but also in adipose tissue, immune and nervous systems [35]. Short chain fatty acids (SCFAs), which are the major metabolic products of anaerobic bacteria fermentation, have been suggested to be the link between microbiota and host 
tissues. SCFAs, also called volatile fatty acids because of their relatively more volatile nature compared to longer fatty acids, have been studied for more than a century. The concentration of these fatty acids in the GIT may predispose to or prevent a large number of pathological conditions. Modifications in the concentrations or the ability of host tissues to use SCFAs have been described in these conditions [6-11].

Acetate, propionate, and butyrate are found in the human intestine at concentrations of approximately $13 \mathrm{mM}$ in the terminal ileum, $\sim 130 \mathrm{mM}$ in the caecum, and $\sim 80$ $\mathrm{mM}$ in the descending colon [12]. They are produced by anaerobic fermentation of non-digestible dietary residues and endogenous epithelial-derived mucus in the gut. SCFAs released in the intestinal lumen are readily absorbed and used as an energy source by colonocytes ( 5 to $10 \%$ of human basal energy requirements are provided by SCFAs) and also by other tissues, including liver and muscle [13]. SCFAs, of which butyrate is the most studied, modulate different processes, including cell proliferation and differentiation, hormone secretion (e.g., leptin and peptide YY) [14,15], and activation of immune/inflammatory responses $[5,16]$. Therefore, in addition to energy supply, these fatty acids have other important functions [18].

The aim of the study was to assess the content of SCFAs in feces of patients with different clinical forms of OLP.

\section{Materials and Methods}

The study included 139 patients (mean age with different clinical forms of OLP in the acute stage. Inspection of the oral cavity was carried out by the usual method (Borovsky EV et al., 2001). The diagnosis of OLP was performed according to both clinical and histopathological criteria [19]. Patients were distributed in four groups according to the clinical form of OLP. Group 1 included 36 patients with the reticular form of OLP; Group 2 included 34 patients with the exudativehyperemic form of OLP; Group 3 included 27 patients with the erosive-ulcerative form of OLP; Group 4 included 42 patients with the bullous form of OLP. The four groups to be compared were randomized by sex and age. The reticular form manifested as bilateral, asymptomatic Wickham striae on the oral mucosa or other parts of the mouth, such as the gingiva, tongue, palate, and lips. The bullous form manifested as fluid-filled vesicles. The erosive form was characterized by ulcerated, painful, erythematous areas.

The control group consisted of 40 healthy, age-matched, randomly selected persons without clinical and instrumental signs of OLP and other diseases of the oral cavity.

A 4-mm punch biopsy was use. The histopathological criteria were a characteristic "saw-tooth" pattern of epidermal hyperplasia; hyperparakeratosis with thickening of the granular cell layer; and vacuolar alteration of the basal layer of the epidermis, with an intense infiltration (mainly T cells) at the dermal-epidermal junction.

The concentration of SCFAs in feces was evaluated by gas-liquid chromatography. We determined: 1) the total concentration of volatile fatty acids; 2 ) the absolute contents of acetic acid (C2), propionic acid (C3), butyric acid (C4); and valeric acid (C5); and 3) the anaerobic index (AI) the ratio of propionic and butyric acids to acetic acid. The profiles (specific concentration) of $\mathrm{C} 2, \mathrm{C} 3$, and $\mathrm{C} 4$ acids were calculated by the formula $\mathrm{pCn}=\mathrm{Cn} /(\mathrm{C} 2+\mathrm{C} 3+\mathrm{C} 4)$; the ratio of iso-acids to straight-chain acids (iso- $\mathrm{Cn} / \mathrm{Cn}$ ) and iso- $\mathrm{C} 5 / \mathrm{C} 5$ were also calculated.

The study was conducted in accordance with the requirements of the WMA Declaration of Helsinki (2008). The study was approved by the Tashkent State Dental Institute Ethics Committee. Written informed consent was obtained from all participants.

Statistical analysis was performed using the statistical software STATISTICA v. 6.0. Baseline characteristics were summarized as frequencies and percentages for categorical variables and as mean $\pm \mathrm{SEM}$ for continuous variables. Student's unpaired t-test was used to compare two groups for data with normal distribution. A probability value of $P<0.05$ was considered statistically significant.

\section{Results}

According to the obtained data, the total absolute content of the studied SCFAs was significantly different from control values in all patients, regardless of the clinical form of OLP; these results indicate changes in the activity of obligate microflora and an increase in the activity of pathogenic and/or opportunistic pathogens.

Three types of SCFA changes reflecting the activity of certain groups of microorganisms were found (Table 1).

Type 1 was characterized by slight changes in the total content, composition, and spectrum of SCFAs, indicating moderate changes in the activity of obligate and facultative anaerobic microflora. Type 2 was characterized by a change in the total number and profiles of $\mathrm{C} 2-\mathrm{C} 4$, indicating the predominant activity of the anaerobic microorganisms, mainly genera Bacteroides, Clostridium, Eubacterium, Fusobacterium, Coprococcus and the strains of the anaerobic microorganisms with proteolytic activity. Type 3 was characterized by changes in the SCFA spectrum, which were associated with the increased activity of the aerobic microorganisms having hemolytic activity (E. Coli, enterococci, streptococci, staphylococci, hemolytic strains of E. Coli, Klebsiella, Proteus, etc.).

For all types of the SCFA disorders, we found a marked increase in the iso- $\mathrm{C} 5 / \mathrm{C} 5$ ratio, indicating an increase in proteolytic activity of facultative, aerobic, and anaerobic microorganisms. The pronounced negative values of the AI ratio, compared with reference values, reflect the changes in the intestinal microflora which contributed to the growth of anaerobic microorganisms.

It should be noted that the severity of dysbiosis increases with the severity of clinical forms of OLP. For example, Type 1 was identified in patients of Groups 1 and 2 with a marked increase in the iso-C5/C5 ratio by $20.67 \%$ and $40.66 \%$, respectively. Type 2 was identified in patients of all groups, with a more marked increase in the iso-C5/C5 ratio (from $74.7 \%$ for Group 1 to $250 \%$ for Group 4). Type 3 was also identified in patients of all groups with an increase in the iso- $\mathrm{C} 5 / \mathrm{C} 5$ ratio by $128 \%$ to $183.3 \%$ (Table 1 ). 
Table 1.

Fecal short-chain fatty acids in patients with different clinical forms of OLP

\begin{tabular}{|c|c|c|c|c|c|c|c|c|}
\hline Group & Type $^{\Delta}$ & $\sum \mathrm{mg} / 1$ & $\mathrm{C} 2(\mathrm{U})$ & $\mathrm{C} 3(\mathrm{U})$ & $\mathrm{C} 4(\mathrm{U})$ & AI & iso- $\mathrm{Cn} / \mathrm{Cn}$ & Iso-C5/C5 \\
\hline \multicolumn{2}{|c|}{ The control group } & $10.28 \pm 0.42$ & $0.638 \pm 0.02$ & $0.188 \pm 0.008$ & $0.174 \pm 0.005$ & $-0.567 \pm 0.02$ & $0.428 \pm 0.02$ & $1.50 \pm 0.07$ \\
\hline \multirow[t]{3}{*}{ Group 1} & I & $12.32 \pm 0.55^{\wedge}$ & $0.602 \pm 0.02^{\wedge}$ & $0.202 \pm 0.008^{\wedge}$ & $0.196 \pm 0.004^{\wedge}$ & $-0.661 \pm 0.03^{\wedge}$ & $0.471 \pm 0.02^{\wedge}$ & $1.81 \pm 0.08^{\wedge}$ \\
\hline & II & $14.32 \pm 0.63^{\wedge}$ & $0.562 \pm 0.01^{\wedge}, *$ & $0.249 \pm 0.01^{\wedge}, *$ & $0.211 \pm 0.008^{\wedge}, *$ & $-0.821 \pm 0.04^{\wedge}$ & $0.503 \pm 0.03^{\wedge}$ & $2.62 \pm 0.11^{\wedge}$ \\
\hline & III & $8.1 \pm 0.31^{\wedge}$ & $0.728 \pm 0.03^{\wedge}$ & $0.123 \pm 0.004^{\wedge}$ & $0,149 \pm 0,006 \bullet$ & $-0.374 \pm 0.008^{\wedge}$ & $0,542 \pm 0,02 \bullet$ & $3.42 \pm 0.12^{\wedge}$ \\
\hline \multirow[t]{3}{*}{ Group 2} & I & $13.21 \pm 0.65^{\wedge}$ & $0.582 \pm 0.02^{\wedge}$ & $0.224 \pm 0.01^{\wedge}$ & $0,194 \pm 0,008^{\wedge}$ & $-0.718 \pm 0.03 \bullet$ & $0.495 \pm 0.02^{\wedge}$ & $2.1 \pm 0.10^{\wedge}$ \\
\hline & II & $14.25 \pm 0.69^{\wedge}$ & $0.546 \pm 0.02^{\wedge}$ & $0.292 \pm 0.01^{\wedge}$ & $0.162 \pm 0.007^{\wedge}, *$ & $-0.832 \pm 0.03^{\wedge}$ & $0.616 \pm 0.02^{\wedge}, *$ & $2.92 \pm 0.12^{\wedge}$ \\
\hline & III & $8.66 \pm 0.38^{\wedge}$ & $0.756 \pm 0.03^{\wedge}$ & $0.118 \pm 0.04^{\wedge}$ & $0.126 \pm 0.004^{\wedge}$ & $-0.323 \pm 0.01^{\wedge},^{*}$ & $0.719 \pm 0.03^{\wedge}, *$ & $4.09 \pm 0.18^{\wedge}, *$ \\
\hline \multirow[t]{2}{*}{ Group 3} & II & $7.26 \pm 0.28^{\wedge}$ & $0.773 \pm 0.03^{\wedge}, \#$ & $0.117 \pm 0.005$ & $0.110 \pm 0.003^{\wedge}, \#$ & $-0.293 \pm 0.01^{\wedge}$ & $0.920 \pm 0.03^{\wedge}$ & $4.61 \pm 0.11^{\wedge}$ \\
\hline & III & $16.23 \pm 0.77^{\wedge}$ & $0.534 \pm 0.02^{\wedge}$ & $0.252 \pm 0.01^{\wedge}$ & $0.214 \pm 0.01^{\wedge}$ & $-0.873 \pm 0.04^{\wedge}$ & $0.760 \pm 0.02^{\wedge}$ & $3.81 \pm 0.08^{\wedge}$ \\
\hline \multirow[t]{2}{*}{ Group 4} & II & $6.81 \pm 0.26^{\wedge}$ & $0.780 \pm 0.03^{\wedge}$ & $0.110 \pm 0.003^{\wedge}$ & $0.110 \pm 0.003^{\wedge}$ & $-0.282 \pm 0.01^{\wedge}$ & $0.854 \pm 0.03^{\wedge}, \#$ & $5.25 \pm 0.25^{\wedge}, \#$ \\
\hline & III & $16.46 \pm 0.81^{\wedge}$ & $0.520 \pm 0.02^{\wedge}$ & $0.250 \pm 0.05^{\wedge}$ & $0.230 \pm 0.01^{\wedge}$ & $-0.923 \pm 0.03^{\wedge}$ & $0.732 \pm 0.02^{\wedge}$ & $4.25 \pm 0.20^{\wedge}$ \\
\hline
\end{tabular}

$\triangle$-Type of SCFA changes; ${ }^{\wedge}-P<0.05$ vs. control; *- $P<0.05$ between Groups 1 and 2; \# - $P<0.05$ between Groups 3 and 4.

Changes in SCFA were obviously due to the increase in activity of anaerobes and activity of aerobic microflora with a strong protolithic and hemolytic activity.

There was a progressive increase in the frequency of the Type 3 SCFA disorders with the increase of the LPO severity (Table 2). In particular, the Type 1 SCFA disorders occurred only in patients with the reticular and exudative-hyperemic forms of OLP. In patients with the reticular form of OLP, the frequency of Type 3 SCFA disorders was $44.44 \pm 8.28 \%$ in comparison with Type I $(22.22 \pm 6.93 \%, P<0.05)$. In patients with the exudative-hyperemic form of OLP, the frequency of Type 3 SCFA disorders was $52.94 \pm 8.56 \%$ in comparison with Type I $(11.76 \pm 5.52 \%, P<0.05)$. The frequency of Type 3 and Type 2 disorders was $70.37 \pm 8.8 \%$ vs. $29.63 \pm 8.79 \%$ $(P<0.05)$ for the erosive-ulcerative form and $61.90 \pm 7.50 \%$ vs. $38.10 \pm 7.56 \%(P<0.05)$ for the bullous form of OLP (Table 2$)$.

Table 2.

Changes in the SCFA spectrum in association with different clinical forms of $O L P$

\begin{tabular}{|l|c|c|c|c|}
\hline Type $^{\wedge}$ & \multicolumn{5}{|c|}{ Clinical form of OLP } \\
\cline { 2 - 6 } & $\begin{array}{c}\text { Group 1 } \\
(\mathrm{n}=36)\end{array}$ & $\begin{array}{c}\text { Group 2 } \\
(\mathrm{n}=34)\end{array}$ & $\begin{array}{c}\text { Group 3 } \\
(\mathrm{n}=27)\end{array}$ & $\begin{array}{c}\text { Group 4 } \\
(\mathrm{n}=42)\end{array}$ \\
\hline I & $8 /(22.2 \pm 6.93) *$ & $4 /(11.8 \pm 5.52)^{*} \#$ & - & - \\
\hline II & $12 /(33.3 \pm 7.85)$ & $12 /(35.3 \pm 8.19)$ & $8 /(29.6 \pm 8.79)^{\wedge}$ & $16(38.1 \pm 7.56)^{\wedge}$ \\
\hline III & $16 /(44.4 \pm 8.28)$ & $18(52.9 \pm 8.56)$ & $19(70.4 \pm 8.80)^{\text {“ }}$ & $26(61.9 \pm 7.50) “$ \\
\hline Total & $36 /(100)$ & $34 /(100)$ & $27 /(100)$ & $42 /(100)$ \\
\hline
\end{tabular}

$\triangle$-Type of SCFA changes;values are presented as $n /(\%) ; *_{-} P<0.05$ between Types 1 and 3 ; \#- $P<0.05$ between Types 1 and $2 ;{ }^{\wedge}-P<0.05$ between Types 2 and 3; "- $P<0.05$ versus Group 1.

\section{Discussion}

Manifestations of OLP are rarely isolated. Patients with OLP often have the comorbid diseases, including disorders in the GIT, which are found between $15 \%$ and $80 \%$ of patients, according to the data of different authors [20-23].
The presence of co-morbidity of different parts of the digestive tract is inevitably accompanied by dysbiosis in the mouth and intestines. Several authors have identified the expressed disbiotic disorders in the oral cavity with OLP [24-27]. Breakdown of the normal microbial community increases the risk of pathogen infection, the overgrowth of harmful pathobionts, and immuno-inflammatory disease. Understanding the interaction of the microbiota with pathogens and the host might provide new insights into the pathogenesis of systemic disorders.

In general terms, patients with LPO exhibit abnormal microbiota with instability of dominant species, which is higher than in healthy controls. High fecal concentrations of total or individual SCFAs might also be the result of increased microbial production, shifts in microbial crossfeeding patterns, and low mucosal absorption. Nevertheless, it is known that changes in the concentration and proportion of individual SCFAs are concurrent with changes in bacterial groups.

SCFAs present multiple effects in different cells involved in the inflammatory and immune responses. In general, SCFAs, such as propionate and butyrate, inhibit stimuli-induced expression of adhesion molecules and chemokine production, and consequently suppress monocyte/ macrophage and neutrophil recruitment, suggesting an antiinflammatory action. However, there is also evidence in favor of a pro-inflammatory action of SCFAs in some conditions $[17,28]$. This discrepancy may be in part explained by the ability of SCFAs to induce neutrophil migration. In sites of anaerobic bacteria infection or after loss of intestinal epithelial integrity, high concentrations of SCFAs may lead to neutrophil accumulation and amplification of the inflammatory process [18]. Another possible explanation is that these fatty acids may present divergent effects depending on the cell type (e.g., antiand pro-inflammatory effects of SCFAs on macrophage and microglial cells have been demonstrated [29-31]. Therefore, although SCFAs modulate the function of immune cells, more studies are necessary in order to understand the precise role of SCFAs on the interaction between bacteria and host 
immune cells in vivo, particularly in the GI tract and in sites of anaerobic infections, including the skin and oral cavity [18].

In conclusion, changes in the qualitative and quantitative contents of SCFAs reflect the disturbances in gut microbiocenosis in LPO patients, which may be one cause for aggravation of the pathological process.

\section{Competing interests}

The authors declare that they have no competing interests.

\section{References}

1. Roopashree MR, Gondhalekar RV, Shashikanth MC, George J, Thippeswamy SH, Shukla A. Pathogenesis of oral lichen planus: a review. J Oral Pathol Med. 2010;39(10):729-34. 2. O'Hara AM, Shanahan F. The gut flora as a forgotten organ. EMBO Rep. 2006;7(7):688-93

3. Diaz Heijtz R1, Wang S, Anuar F, Qian Y, Björkholm B, Samuelsson A, et al. Normal gut microbiota modulates brain development and behavior. Proc Natl Acad Sci USA. 2011;108(7):3047-52.

4. Vijay-Kumar M, Aitken JD, Carvalho FA, Cullender TC, Mwangi S, Srinivasan S, et al. Metabolic syndrome and altered gut microbiota in mice lacking Toll-like receptor 5. Science 2010;328(5975):228-31.

5. Maslowski KM, Vieira AT, Ng A, Kranich J, Sierro $\mathrm{F}$, YuD, et al. Regulation of inflammatory responses by gut microbiota and chemoattractant receptor GPR43. Nature. 2009;461(7268):1282-6.

6. Huda-Faujan N, Abdulamir AS, Fatimah AB, Anas OM, Shuhaimi M, Yazid AM, Loong YY. The impact of the level of the intestinal short chain_Fatty acids in inflammatory bowel disease patients versus healthy subjects. Open Biochem J. 2010;4:53-58.

7. Vernia P, Caprilli R, Latella G, Barbetti F, Magliocca FM, Cittadini M. Fecal lactate and ulcerative colitis. Gastroenterology. 1988;95(6):1564-8.

8. Murphy EF, Cotter PD, Healy S, Marques TM, O'Sullivan $\mathrm{O}$, Fouhy F, et al. Composition and energy harvesting capacity of the gut microbiota: relationship to diet, obesity and time in mouse models. Gut. 2010;59(12):1635-42.

9. Schwiertz A, Taras D, Schafer K, Beijer S, Bos NA, Donus C, Hardt PD. Microbiota and SCFA in lean and overweight healthy subjects. Obesity. 2010;18(1):190-5.

10. Simark-Mattsson C, Eklund S. Reduced immune responses to purified protein derivative and Candida albicans in oral lichen planus. J Oral Pathol Med. 2013;42(9):691-7.

11. Petrova LV. Clinical features of lichen planus of the oral mucosa. Ross Zh Kozh Vener Bolezney. 2002;3:28-31.[Article in Russian].

12. Cummings JH, Pomare EW, Branch WJ, Naylor CP, Macfarlane GT. Short chain fatty acids in human large intestine, portal, hepatic and venous blood. Gut. 1987;28(10):1221-7.

13. McNeil NI. The contribution of the large intestine to energy supplies in man. Am J Clin Nutr.1984;39:338-42.

14. Zaibi MS, Stocker CJ, O'Dowd J, Davies A, Bellahcene M, Cawthorne MA, et al. Roles of GPR41 and GPR43 in leptin secretory responses of murine adipocytes to short chain fatty acids. FEBS Lett. 2010; 584(11):2381-6.

15. Plaisancie P, Dumoulin V, Chayvialle JA, Cuber JC. Luminal peptide YY-releasing factors in the isolated vascularly perfused rat colon. J Endocrinol. 1996;151(3):421-9.
16. Vinolo MA, Rodrigues HG, Hatanaka E, Sato FT, Sampaio SC, Curi R. Suppressive effect of short-chain fatty acids on production of proinflammatory mediators by neutrophils. J Nutr Biochem. 2011; 22(9):849-55.

17. Vinolo MA, Rodrigues HG, Hatanaka E, Hebeda CB, Farsky SH, Curi R. Short-chain fatty acids stimulate the migration of neutrophils to inflammatory sites. Clin Sci. 2009;117(9):331-8.

18. Vinolo MA, Rodrigues HG, Nachbar RT, Curi R. Regulation of Inflammation by Short Chain Fatty Acids. Nutrients. 2011; 3(10): 858-76.

19. Kraft R, Usatine RP. Lichen planus. In: The Color Atlas of Family Medicine. Usatine RP, Smith MA, Chumley H, Mayeaux EJ Jr., Tysinger J, eds. New York, NY: McGrawHill; 2009:634-639.

20. Beleva NS, Libik TV. Factors systemic risk in patients with manifestations of lichen planus of the oral mucosa. Proceedings of the All-Russian scientific-practical conference of students, graduate students and young scientists. Perm, 2009:191-4. [Article in Russian].

21. Surdina ED. Modern conceptions of the leading factors in development and treatment of lichen planus with manifestations in the oral mucosa. Vestnik St. Petersburg University. Ser.11. 2011;4:112-118. [Article in Russian].

22. Oskolsky GI, Zagorodnaya EB. Role of dysbiotic shifts in patients with lichen planus of the oral mucosa. In: Actual problems and prospects of development of dentistry in the North. Ushnitskii ID, ed. Yakutsk, NEFU; 2011:170-174.

23. Ron GI, Epishova AA. Modern ideas about the etiology and pathogenesis of lichen planus of the oral mucosa (review). Problemi Stomatol. 2011;4:15-17. [Article in Russian].

24. Slujaev IF, Oskolsky GI, Zagorodnaya EB. Oral lichen planus of the oral mucosa: clinical features, treatment. Dal'neVostochniy Med Zh. 2010;2:132-136. [Article in Russian].

25. Pourshahidi S, Fakhri F, Ebrahimi H, Fakhraei B, Alipour A, Ghapanchi J, Farjadian S. Lack of association between Helicobacter pylori infection and oral lichen planus. Asian Pac J Cancer Prev.2012;13(5):1745-7.

26. Taghavi Zenouz A, Mehdipour M, Jafari Heydarlou M, Gholizadeh N. Relationship between lichen planus and Helicobacter pylori infection. J Dent Res Dent Clin Dent Prospect. 2010;4(1):17-20.

27. Ardatskaya MD, Dmitrieva LA, Khubutia BN, Georgieva OA, Osipov TL. The study of oral microflora metabolites (short chain fatty acids) in patients with lichen planus; diagnostic and tactical importance. Estestv Tekhnich Nauki. 2012;6(62):194-204. [Article in Russian].

28. Niederman R, Buyle-Bodin Y, Lu BY, Robinson P, Naleway C. Short-chain carboxylic acid concentration in human gingival crevicular fluid. J Dent Res. 1997;76(1):575-9. 29. Halili MA, Andrews MR, Labzin LI, Schroder K, Matthias G, Cao C, et al. Differential effects of selective HDAC inhibitors on macrophage inflammatory responses to the Tolllike receptor 4 agonist LPS. J Leukoc Biol. 2010;87(6):1103-14. 30. Bailon E, Cueto-Sola M, Utrilla P, RodriguezCabezas ME, Garrido-Mesa N, Zarzuelo A, et al. Butyrate in vitro immune-modulatory effects might be mediated through a proliferation-related induction of apoptosis. Immunobiology. 2010;215(11):863-73.

31. Huuskonen J, Suuronen T, Nuutinen T, Kyrylenko $\mathrm{S}$, Salminen A. Regulation of microglial inflammatory response by sodium butyrate and short-chain fatty acids. Br J Pharmacol. 2004;141:874-80. 